\title{
VALUE ANALYSIS TO IMPROVE SYSTEM ARCHITECTING
}

\author{
Lalevée, Alexis $(1,2,3)$; \\ Troussier, Nadège (1); \\ Blanco, Eric $(2,4)$; \\ Chakroun, Mahmoud (3) \\ 1: Université de Technologie de Troyes - CREIDD; \\ 2: Univ. Grenoble-Alpes - Grenoble-INP, G-SCOP; \\ 3: Euro Contrôle Projet; \\ 4: Ecole de l'Air BA701
}

\begin{abstract}
Value Analysis (VA) is a collaborative method that could be used to make a decision in the early phase of complex projects. In this framework, Stakeholders are involved into the process of decisionmaking and project success is facilitated. Systeme Architechting (SA) is a set of processes used for the conceptual phase of the design of complex systems while System Engineering (SE) is the set of processes used for the design phase of the system. In complex projects, Stakeholders are multiple and carry specific technical, social and environmental expectations that define their perceived Value of the project. The aim of this paper is to demonstrate that VA and SA are two complementary approaches to collect and analyse Stakeholder needs in a complex project. The article presents an analysis of the literature review on VA and SA / SE. Based on this analysis, an illustration case is proposed to show how to integrate VA into SA to understand the needs of Stakeholders. The article concludes that the two methods VA and SA can be combined to analyze and would allow following several dimensions of Value (economic, social and environmental) within a complex project.
\end{abstract}

Keywords: Systems Engineering (SE), Value Analysis, Stakeholder, Collaborative design, Ecodesign

\section{Contact:}

Lalevée, Alexis

University of Technology of Troyes

CREIDD

France

alexis.lalevee@utt.fr 


\section{INTRODUCTION: THE STAKES OF EARLY DESIGN OF COMPLEX SYSTEMS}

Our study focuses on the integration of social and environmental dimensions into decision-making processes upstream of the design of complex systems. The interest in these upstream (or conceptual) phases comes from the fact that they have a strong impact on the entire life cycle of the system while having a limited commitment of resources. As highlighted by (Kolltveit and Grønhaug, 2004), it is recognized that the quality of the execution of the early project phases is critical to project performance. This makes this phase as the most interesting phase to make decisions and that is why we are interested in it. In our approach, we define complex systems as systems designed during complex projects. Thus, they have the following characteristics: 1) different technologies coexist in the same system which operates over a period of time that exceeds the technology cycle time of the technologies involved, 2) Stakeholders with very different interests must be taken into account and 3) the system must meet many very different needs (Hass and Lindbergh, 2010; Yang et al., 2019). Thus, we could summarize the complexity by uncertainties at different levels in a sociotechnical system. This complexity creates difficulties in early decisions for the design of complex systems. Indeed, two "dimensions" of the project are implemented to make a decision in order to achieve a complex project, with a dynamic point of view as shown by (Lyneis, Cooper and Els, 2001). On the one hand, the management of the resources implemented but also of the various Stakeholders who must be involved in the project for it to succeed. On the other hand, there is the design dimension: what choices can be made with the information that is available at this design level of the system? What indicators can support these design choices and what is their level of reliability? These two dimensions must be managed simultaneously and indicators and support must come to underpin the decision-making, which is mainly made by decision-makers who are the funders.

However, in complex system, the value is multiple and includes not only technical and financial dimensions, but also dimensions related to the social and environmental expectations of Stakeholders.

The challenges in these upstream design phases are therefore to integrate and build a shared vision of the project and its value that will be perceived by all the Stakeholders.

If there is no Stakeholder support for the project, this can lead to either legal fights and appeals which can lengthen the project design timeframe; but this can even lead to the abandonment of the project. One of the most representative examples is that of the "Grand Ouest airport project", near Nantes in France. This project was launched in 1963 and was finally abandoned in 2018 after years of fighting by residents and associations who did not want this project. The results of this strategic project for the French government are the additional costs linked to the extension of the project and the various studies carried out, a tense social climate and the mistrust of the inhabitants and of various associations. This project ends with an abandonment.

The aim of this paper is to understand how it is possible to combine VA and SA in order to facilitate collaboration between management and technical actors to achieve Stakeholder expectations linked to sustainable issues, as social and ecological ones. The methodology is composed at first by a literature review to compare VA and SA through their capacity to perform Stakeholder requirements. Our proposal is to use the VA methodology to complete the analysis of the needs of Stakeholders in an SA approach. We will then illustrate this proposal with a case from a company that aims to complete the SA approach with the VA. Based on these two observations, the authors will conclude that VA and SA can be used in the same project and discuss the advantages and limitations of this proposal.

\section{STATE OF THE ART ON THE METHODS AND TOOLS USED FOR EARLY DESIGN OF COMPLEX SYSTEMS}

The starting point of our study is the observations of practitioners in project management and system design. Working together on projects, practitioners have noticed quite similar approaches, both of which seek to enable monitoring of design indicators and integration of Stakeholder needs. Indeed, we were able to discuss with people who deal with the upstream phase of system design and we were able to realize that in practice, two approaches are used and mainly developed: it is the Value Analysis approach (VA) and the System Engineering approach (SE). We relied on the existing professional networks of AFAV (French Association for Value Analysis) mainly as well as 
joint conferences with AFIS (French Association of System Engineering) to conduct these observations.

We will describe in the two following sections what VA and SE are and how they are used.

\subsection{Value Analysis}

Value Analysis is supported by different standards as (NF X50-152:2007-09, 2007; NF EN 1325:2014-04, 2014), used in Europe to frame its applications. Originally, VA was defined as a costcutting tool, allowing redesigning products more competitively (Fernandes, 2015). It is a reduced vision of the calculation of the Value defined as a balancing between the needs and the costs associated with it. This approach permits the extension of applications of the concept into other levels of management. Many different works and applications had developed the concept and the methods associated, as described by (Fernandes, 2015): "We can find a tremendous number of different learning exercises and theoretical evolution from that work, but that has not yet answered many aspirations regarding the initial concept of value and value analysis. VA has evolved or is yet evolving. It shows that the method is able to be adapted to many situations". Indeed, (Fernandes, 2012)introduce cultural values as a factor influencing the measure of perceived Value, for instance. Other approaches had shown that VA is a method able to support Sustainability in early phases of a complex project (Lalevée et al., 2020).

Concerning the Stakeholder approach in VA, the concept of value was firstly customer centric as described in the 1995 European standard (European Comission, 1995) and became stakeholder-based (NF EN 1325:2014-04, 2014) in the last standards. It reflects an adaptation of the guidelines to socioeconomic requirements: it is now essential that the reflection around the design of the system be done in collaboration with all the Stakeholders of the project. Thus, we can say that there exist multiple possible views due to multiple applications of the methodology. As underlined by (Bowen et al., 2010), VA uses the workshop system to produce brainstorming synergies. This collaborative work is used to support decision-making in project management. Stakeholders are involved in and throughout the project and its chances of success are optimized. The method is based on a Functional Approach (FA) that treats functions that respond to stakeholders' requirements and systems finalities, it is to say, "what the system is supposed to do". However, this method is completed with another approach that treats positive or negative externalities of the system: non-functional needs. They are treated and used to compare some solutions proposed within different scenarios. These other needs are often subjective and difficult to estimate. They are mainly based on social or environmental issues as the quality of life at work or corporate branding. All along the method, a collaborative work in group is used to permit collective intelligence and a VA leader is designated to assure good practices. Often consultancy companies play that role. From the practitioner's point of view of the VA, Stakeholders are managed within workshops to elicit the multiple dimensions of the perceived Value of the project.

To conclude, we can say that Value Analysis (VA) is a well-known method to deal with complex project value. It is able to be adapted in many contexts (Fernandes, 2015) and has a stakeholderscentered approach. Thus, VA is used to support decision-making especially in the early phases of projects, when needs and principle of solutions are defined. This approach helps practitioners to better frame their projects and thus obtain greater performance thanks to a calculation of the Value based on the balancing of the needs and the costs associated with it.

As described earlier, another approach used in the industry aims to design projects and support decisions from the upstream design phases: this is System Engineering (SE), which we will describe below.

\subsection{System Engineering}

With a general viewpoint, "SE is a transdisciplinary approach and means to enable the realization of successful systems. Successful systems must satisfy the needs of their customers, users and other stakeholders", (INCOSE and IEEE Computer Society, 2016). According to the general guide (INCOSE, 2016), SE approach is guided by a stakeholder-centered approach. However, with a more detailed study, we can find that:

Stakeholders are questioned at the beginning of the project, during the "architecting phase", according (INCOSE and IEEE Computer Society, 2016)

Their requirements are relieved with questionnaires (Malviya et al., 2017). This research is based on a specific phase of SE study dedicated to stakeholders' requirements elicitation. 
Requirements correspond to a very technical view of Stakeholders needs: as illustrated by (INCOSE and IEEE Computer Society, 2016), "a systems engineer helps ensure the elements of the system fit together to accomplish the objectives of the whole, and ultimately satisfy the needs of the customers and other stakeholders who will acquire and use the system".

A non-specific view of the context of the project is proposed: according to (Malviya et al., 2017), some artefacts are researched and used.

These observations conducted us to determine some limits of the SE view of stakeholders-centered system as the fact that involvement of Stakeholders seem to be limited by the method used. This is supported by the fact that other work has been carried out to address this lack of Stakeholder involvement and rapid iterations as described by (Batista, Hassan and Bonjour, 2020). However, we will study the architecting phase, which interests us the most because of its potential impact on the entire lifecycle and we will focus on the requirements of Stakeholders and the indicators used. In fact, this conceptual phase, during which the major design trends are taken, has a significant interest for the company which was at the origin of this reflection. We are going to focus more particularly on this phase of architecting and on System Architecting (SA), which can be described as one of the constitutive processes of SE.

According to (Maier and Rechtin, 2000), SA is described as an art in the sense that it wants to be able to translate non-measurable dimensions such as human dimensions, personal values but also performance, when science is not able, to make design decisions. Nevertheless, (Maier and Rechtin, 2000) recognizes that "not surprisingly, architecting is often individualistic, and the end results reflect it". Indeed, with a practical approach as described in the general introduction of SE, two points need to be highlighted: all the stakeholders of the system are not necessarily taken into account as it is a clientcentered approach (Maier and Rechtin, 2000); and the interactions between the architecting engineer, the system designer in the design phase and the «client » is not easy. In fact, with a very practical viewpoint, the "client" is interrogated through questionnaires, as described in the general description made of the SE. In summary, in early design phases, SE is involved especially by SA methodology. We will then focus on it for the following sections of this paper.

To conclude, we have seen that two approaches are mainly used to design a complex system, during the upstream phases: Value Analysis (VA) and System Architecting (SA). VA is a Stakeholdercentered approach to a project. It aims to provide decision-making support, in the upstream design phases, which provides a systemic view of the perceived value of the project. VA approach makes it possible to create and share a common vision of the system. SE and more precisely SA aims to design systems by integrating the parameters allowing meeting all the expected needs. However, this approach remains very dependent on the architect who designs the system.

We are therefore going to focus on 1) understanding the limits of SE and more particularly of SA for collaborative decision-making integrating Stakeholders and the diversity of dimensions of Value and 2) understanding how VA can help bridge these limits.

For this, the methodology used is as follows:

- a theoretical analysis of the two approaches, VA and SA, allowing to understand what are the limits of SA for collaborative decision making and how SA can address these limits

- a proposal for a combination of VA and SA to better support decision making in early phase and throughout the design process, with a theoretical description and then an illustration of the proposal on an example of an upstream design of a complex system

- discussions around this proposal and the observations made.

\section{PROPOSAL}

Our proposal is to use the VA methodology to complete the analysis of the needs of Stakeholders in an SA approach. We will first see what the complementarities between these two approaches are, then how to implement them.

\subsection{Theoretical analysis of SA and VA}

In the two following subsections, we will present the limits of SA for collaborative decision-making and we will identify the potential for VA to address these limitations. 


\subsubsection{The limits of SA for collaborative decision-making and integrating the diversity of decision criteria}

As described during the literature review, despite the fact that SA is intended to be a holistic approach to integrating all the features necessary for the design of a complex system, the point is that it is a customer-centric approach. This approach does not allow to have a systemic vision on the contributions and the impacts of the system, during its whole life cycle since this client focuses on what interests him, the operating phase. Indeed, with the client point of view, what is interesting is exploiting the system to create value. In addition, this vision prevents taking into account all the Stakeholders for whom the system will have contributions (utility, financial, etc.) but also impacts (social, environmental, etc.). Moreover, it is based on individual work by the architect who is responsible for transcribing (the client's) needs into system requirements. Thus, the architect is the only one who can judge the relevance and completeness of the information that will subsequently be used in the design phase of the system.

The SA approach does not make it possible to have a global and enlightened vision of the needs of the Stakeholders despite the fact that they are able to delay or even cancel a project to design a complex system. This is why we propose in the next subsection to focus on what VA could bring within the stated limits.

\subsubsection{Identification of the potential of VA to address these limits}

As described during the literature review, VA is a very flexible method based on collective work used to support decision in early phases of complex system design. It helps practitioners to determine what are real needs of Stakeholders. All Stakeholders are involved in the design process. This not only allows to have a systemic view of the system, including all the phases of its life cycle; but it also makes it possible to have a consensus, a shared vision of the project and the perceived value that results from it.

Table 1 proposes a comparison between VA and SA approaches to manage Stakeholder requirements, considering methods handbooks, standards and scientific approaches. The analysis focuses on the objectives of each approach, the involvement and the needs identification for each approach, based on Stakeholders.

Table 1. Comparison of VA and SA approaches based on Stakeholders

\begin{tabular}{|c|c|c|}
\hline & \multicolumn{2}{|c|}{ Approaches } \\
\hline & Value Analysis & System Architecting \\
\hline $\begin{array}{l}\text { High-level objectives (NF X50- } \\
\text { 152:2007-09, 2007; ISO/IEC/IEEE } \\
\text { 42020:2019:2019-07, 2019) }\end{array}$ & $\begin{array}{l}\text { Increase the value of a } \\
\text { project by defining the } \\
\text { real needs of } \\
\text { Stakeholders }\end{array}$ & $\begin{array}{r}\text { Definition of the } \\
\text { problematic }\end{array}$ \\
\hline \multirow[t]{2}{*}{$\begin{array}{l}\text { Stakeholders' involvement (Maier and } \\
\text { Rechtin, 2000; NF X50-152:2007-09, } \\
\text { 2007; Fernandes, 2015) }\end{array}$} & $\begin{array}{l}\text { As soon as the definition } \\
\text { of the objectives of the } \\
\text { project }\end{array}$ & At the start of the process \\
\hline & Workshops & $\begin{array}{r}\text { Questionnaires and } \\
\text { interviews }\end{array}$ \\
\hline \multirow{4}{*}{$\begin{array}{l}\text { Stakeholders' requirements/needs } \\
\text { (Maier and Rechtin, 2000; NF X50- } \\
\text { 152:2007-09, 2007; Fernandes, 2015) }\end{array}$} & $\begin{array}{l}\text { At the start of the project } \\
\text { with permanent iterations }\end{array}$ & At the start of the project \\
\hline & $\begin{array}{l}\text { All Stakeholders of the } \\
\text { project }\end{array}$ & User / customer centric \\
\hline & Collectively discussed & Individually determined \\
\hline & Workshops & $\begin{array}{r}\text { Questionnaires and } \\
\text { interviews }\end{array}$ \\
\hline \multirow[t]{2}{*}{$\begin{array}{l}\text { Decision-making (Maier and Rechtin, } \\
\text { 2000; NF X50-152:2007-09, 2007; } \\
\text { Fernandes, 2015) }\end{array}$} & $\begin{array}{l}\text { Based on the support } \\
\text { established collectively } \\
\text { during the workshop }\end{array}$ & $\begin{array}{l}\text { Based on users / } \\
\text { customers needs }\end{array}$ \\
\hline & Decision-makers & Architect / Engineer \\
\hline
\end{tabular}


Let us consider the two approaches used in the upstream phase of the project. They both serve to conceive major design tendencies. However, the methods for identifying and characterizing needs differ. If the VA uses an approach based on the collective intelligence of a group, the SA has a more individual approach. The framework used during these studies explains this: the VA aims to take into account and integrate all the Stakeholders while the AS is interested in the end customer. As we have described before, this user or customer centric approach today represents a strong limit for the acceptance of projects. New parameters, supported by many Stakeholders, are based on the principles of Sustainability where the human being must take precedence over technology. SA does not seem to be adapted to these changes. This is why we propose in the following section to show how the VA can be used to implement the SA to define the needs of the Stakeholders and thus ensure their involvement.

These observations come to consolidate the observations made by the practitioners resulting from the two approaches that try to collaborate. To this are added the observations made by (de Graaf et al., 2019) which proposes different axes such as the treatment of Stakeholders or the definition of Value so that the VA complements the SE. Thus, we propose to combine VA and SA to support decisionmaking in early phases of complex system design. It will be described in the following section.

\subsection{Proposal of a combination of SA and VA to better support decision making in early phase and throughout the design process}

Our proposal aims to provide decision-making support in the conceptual phases of the design of complex projects. It will allow all the Stakeholders to be included in the process of establishing decision-making support, based on their real needs.

\subsubsection{Theoretical description of the proposal}

The proposal is a mixed approach of VA used to identify real needs of Stakeholders and support decision-making of the architect. Thus, VA is a tool to support the SA decision-making. The first step consists to identify all the Stakeholders of the project and their needs. We propose, as in a classical VA, to set up a working group with these Stakeholders. The working group will have the same role of support but no longer for the final decision-maker but for the architect of the system. Indeed, the working group will deal not only with functional elements as defined previously but also with nonfunctional dimensions. The indicators used in VA, exchanges and consensus will make it possible to establish which needs must be taken into account. We propose to establish a classification of these in order to know their order of priority. When these needs are identified and characterized, the architect translates them in the form of technical requirements as in a classic SA approach.

The advantage of this approach is that all the Stakeholders are involved in the system design process and that the architect does not find himself making decisions on purely technical criteria, with little hindsight.

With a theoretical approach, it seems that the combination of VA and AS could be used to support decision-making early in design. We will support our remarks with the illustrative case described below.

\subsubsection{Illustration of the interest of the proposal on an example of early design situation}

The case presented thereafter was used to demonstrate that VA is a method able to introduce sustainability issues into project management (Lalevée et al., 2020). The case used is about the design of a transportation facility and policy between two cities A and B far from about twenty kilometres from one another. The objective of the project is to find some solutions to link up A to B globally more efficiently. In fact, existing small roads between $\mathrm{A}$ and $\mathrm{B}$ are overloaded and a highway exists near to B from North to South without any exit to lay out B. Furthermore, some residential subdivisions were built on the outskirts of both cities; a river is situated at a few hundred meters of A and B South's limits, and there is a mountain to the North. These topological constraints do not let us think about an "easy" solution. A consulting company is solicited by the Government to determine what is the project (management and Stakeholders) which would design the best solution.

Value of the project is complex since it has multiple dimensions: social, political, economics and environmental. Many stakeholders are concerned by the project. Multiple solutions exist with complex links between Stakeholders and with coupled dimensions that make the complexity of it. 
The first step is to identify the Stakeholders of the design project. The Government, the inhabitants of the two cities, the future constructors of the solution, the various managers of the means of transport (...) are identified. When the Stakeholders are identified, it is then necessary to identify what their needs are in relation to this project. For this, workshops are organised, in order to discuss and reach a consensus. Thus, the needs expressed relate to functional needs like "to transport people" or "to facilitate exchanges"; but also non-functional needs like "to have a positive impact on the environment". These needs are treated with an adequate analysis, always in groups, in order to define which functional needs to be privileged and which are optional. The most important function is "to transport people" that is noted with $65 \%$ of the importance of the project while "to facilitate exchanges" have $35 \%$ of Stakeholders preferences. Next step is to define what are the possible solutions. After an ideation phase, always in groups, these are evaluated: the technical solutions, according to their feasibility and their response to the main needs. For example, a land and air solution will both meet the problem of transporting people, but air transport seems to be more limited for its contribution to trade. Subsequently, other, non-functional factors are used to evaluate the different solutions. Thus, after agreeing on the criteria for evaluating the "beauty" of the system, the group of work evaluates each of the proposals: the idea of air transport, although it responds to our problem of transporting people and to facilitate exchanges, calls for the construction of infrastructures deemed intolerable on the territory by the inhabitants. In addition, there are financial constraints that mean that, in its report, the working group favors means of land transport. These recommendations from the Stakeholders feed the architect who integrates his information into the system design process. By integrating these real needs, stated by the Stakeholders, the success of the project will be facilitated. Thus, the output deliverable of this first phase of architecture is not only a report of recommendations from various Stakeholders but also the System Requirements that will be used and integrated into the system design process.

After describing how VA and SA could be implemented to achieve decision support early and throughout the design process, we will now discuss these results.

\subsection{Discussions}

With a VA approach, the group of work makes it possible to have a systemic approach to the problem, with different points of view, exchanges and consensus. It also allows Stakeholders to get involved in the project and thus to feel involved in it. This approach makes it possible to understand the real need of each of these Stakeholders.

With a SA approach, the client focuses on the user of the system: in fact, it is the latter who will judge its performance. The architect, who will translate the needs into requirements of the system, will have a very technical approach: he translates the needs in relation to a future use. Thus, design decisions are centered on the use and the customer.

Our proposed mixed approach makes it possible to integrate the Stakeholders and their opinions in the upstream design phases. Thus, the major orientations can be supported. The work of the architect is more substantial and requires more time since he must integrate into the requirements of the system functional needs technically translated by performance, but also non-functional needs which are more difficult to translate into System Engineering.

\subsubsection{The architecting approach vs the Value Analysis approach}

VA approach not only allows collective intelligence through exchanges carried out during the phases of the project but also the involvement of Stakeholders. From a decision-making point of view, the advantages of SA are linked to speed: the engineer is based on his knowledge of the customer's needs which he expresses in the form of technical requirements.

With a more applicative approach, we have seen that the Stakeholders take an important part of the VA approach: they are questioned through work of groups throughout the project. With the experience management practitioners, we can add that they are crucial elements for the success of a project. (Kolltveit and Grønhaug, 2004) confirm this element.

\subsubsection{The interest of an integrated approach of Stakeholders}

As evocated earlier, Stakeholders are key elements of the success of a project. As highlighted by (INCOSE and IEEE Computer Society, 2016): "Understanding the needs of all stakeholders inside and outside the company" take part of major activities of a SE approach. We have seen above that VA and 
SA approaches are complementary to involve Stakeholders in a complex project. In fact, if they seem to be complementary, both methods have particularities as the method to interrogate the "Stakeholders".

VA seems to be a method capable of integrating Stakeholders during early phases of the project and continuing interrogating them all along the project. Moreover, the approach permits a Stakeholder involvement and decision-making that is not only based on technical aspects. It is why VA is complementary to SA that is based on Stakeholders needs and treated mainly by system engineers with a technical approach. This aspect of the complementarity is reinforced by (de Graaf et al., 2019): in fact, their works show that SE have to optimise Stakeholders' perceived value of a system and show that VA could be a tool of SE process.

\subsubsection{Recommendations for practitioners}

The first recommendation concerns the framework of the design: the customer is certainly important but today, the designers can no longer not take into account all the Stakeholders with all the complexity associated with it. The involvement of Stakeholders in the project is a guarantee of its acceptance.

The second recommendation concerns needs. Indeed, the requirements of the system which are the translation of the expressed need must not only be functional but dimensions such as the social, human or the environment, as well as the different personal and cultural values must be able to be included. A VA approach will not only identify and characterize needs but also ensure the involvement of Stakeholders in complex projects.

As described previously, some limits still exist but we believe that VA and SA or even SE could allow better monitoring of the design of complex systems.

\subsubsection{Limits of this work and future works identified}

The lack of data interchangeability is the first limiting aspect in the integration of Value Analysis in System Architecting and even more generally in System Engineering. In the upstream phase, this is limited since the group of work supports the work of the architect. However, in order to be able to iterate, the available data must also be exploitable by the working group. Thus, the interface between the two methods is one of the elements that should be studied in our future research so that exchanges are possible throughout the life cycle of the system and its design. In fact, exchanging with practitioners, it seems that this aspect is crucial to be studied in future works to use together the two approaches to obtain a global process able to take into account and integrate Stakeholder requirements all along a complex project. Another limit linked to this aspect concern the vocabulary. Indeed, VA and SA use very similar terms but with different meanings. This is a limit to our work that must be taken into account: how will practitioners manage to collaborate if they are not able to dialogue? Here again, more in-depth work should be carried out in order to determine what would be the means for practitioners to understand each other (glossary? Diagrams? Graphics?)

Finally, if it is used in practice, there is today a lack of scientific perspective on VA / SE and SA complementarities. We could say that there is a lack of hindsight on the approaches, techniques and methods that would be able to implement the SE, whether in the understanding of the needs, the integration of the Stakeholders, the optimization of the perceived value of systems, the integration of sustainability... These lines of research seem particularly interesting to us for the current and future evolutions of the approaches allowing to integrate social and environmental dimensions in the decision-making processes from the upstream phases of the design of complex systems.. For example, a comparative work could be carried out between the Design Thinking approaches undertaken by (Batista, Hassan and Bonjour, 2020) and our works based on Value Analysis.

\section{CONCLUSION}

This article allowed us to better understand the limits of SE and more particularly of SA for collaborative decision-making integrating Stakeholders and the diversity of dimensions of Value and it permits to better understand how VA can help bridge these limits also.

We have demonstrated that the VA, combined with an SE approach allows 1) to better integrate the Stakeholders in the decision-making process of the SA thanks to the use of a collaborative process of construction of the specifications resulting from the VA. The combination of the two approaches also 
makes it possible 2) to integrate a greater diversity of criteria making it possible to define the Value of a system: the model based on the "needs / costs" ratio is extended beyond the current financial and technical values used in the evaluation of complex systems projects. To integrate VA in a SE framework could be a support to improve socio-technical systems design as described by (Baxter and Sommerville, 2011).

\section{REFERENCES}

Batista, J., Hassan, A. and Bonjour, E. (2020) 'Design Thinking to enhance Requierements Analysis in Systems Engineering', in International Design Conference, pp. 2255-2264.

Baxter, G. and Sommerville, I. (2011) 'Socio-technical systems: From design methods to systems engineering', Interacting with Computers. Elsevier B.V., 23(1), pp. 4-17. https://dx.doi.org/10.1016/j.intcom.2010.07.003.

Bowen, P. et al. (2010) 'Value management practice by South African quantity surveyors', Facilities, 28(1), pp. 46-63. https://dx.doi.org/10.1108/02632771011011396.

European Comission (1995) Value Management - handbook, Facilities Management: Theory and Practice. https://dx.doi.org/10.4324/9780203475966.

Fernandes, M. T. (2012) 'A Holistic and Cultural view of Value', Advances in Management \& Applied Economics, 2(1), pp. 55-107.

Fernandes, M. T. (2015) 'Value Analysis: Going into a further dimension', Engineering, Technology \& Applied Science Research, 5(2), pp. 781-789. Available at: www.etasr.com.

de Graaf, R. et al. (2019) 'Value Engineering as a Specialty for Systems Engineering: Exploring Opportunities', Insight, 22(1), pp. 41-44. https://dx.doi.org/10.1002/inst.12237.

Hass, K. B. and Lindbergh, L. B. (2010) 'The bottom line on project complexity: Applying a New Complexity Model', in PMI ${ }^{\circledR}$ Global Congress 2010-North America, Washington, DC. Newtown Square, PA: Project Management Institute, pp. 1-16. Available at: https://www.pmi.org/learning/library/project-complexitymodel-competency-standard-6586.

INCOSE and IEEE Computer Society (2016) Guide to the Systems Engineering Body of Knowledge (SEBoK), Guide to the Systems Engineering Body of Knowledge (SEBoK). Available at: http://g2sebok.incose.org/app/mss/menu/index.cfm.

ISO/IEC/IEEE 42020:2019:2019-07 (2019) 'Software, systems and enter pr ise - Architecture processes', International Organization for Standardization, Geneva, Switzerland.

Kolltveit, B. J. and Grønhaug, K. (2004) 'The importance of the early phase: The case of construction and building projects', International Journal of Project Management, 22(7), pp. 545-551. https://dx.doi.org/10.1016/j.ijproman.2004.03.002.

Lalevée, A. et al. (2020) 'The interest of an evolution of Value Management methodology in Complex Technical Projects for improving Project Management', Procedia CIRP, 'Life Cycle Engineering' 2020 conference, 90, pp. 411-415. https://dx.doi.org/10.1016/j.procir.2020.01.108.

Lyneis, J. M., Cooper, K. G. and Els, S. A. (2001) 'Strategic management of complex projects: A case study using system dynamics', System Dynamics Review, 17(3), pp. 237-260. https://dx.doi.org/10.1002/sdr.213.

Maier, M. W. and Rechtin, E. (2000) The Art of Systems Architecting - Second edition. https://dx.doi.org/10.1201/9781420058529.

Malviya, S. et al. (2017) 'What Questions do Requirements Engineers Ask?', Proceedings - 2017 IEEE 25th International Requirements Engineering Conference, RE 2017, (September), pp. 100-109. https://dx.doi.org/10.1109/RE.2017.76.

NF EN 1325:2014-04 (2014) 'Value Management — Vocabulary — Terms and definitions', Association française de normalisation, La Plaine Saint-Denis, France.

NF X50-152:2007-09 (2007) 'Value management - Basic characteristics of value analysis', Association française de normalisation, La Plaine Saint-Denis, France.

Yang, L. et al. (2019) 'Integrated design of transport infrastructure and public spaces considering human behavior: A review of state-of-the-art methods and tools', Frontiers of Architectural Research. Elsevier, 8(4), pp. 429-453. https://dx.doi.org/10.1016/J.FOAR.2019.08.003. 


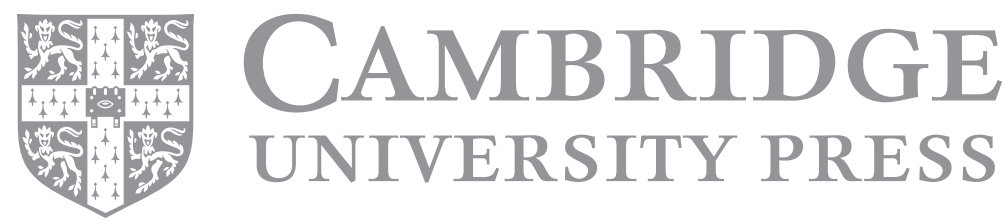

